\title{
Inverse ' $D$ ' incision technique in treatment of pilonidal sinus disease; excision with minimal tissue loss, closure without tension and lateral location of the suture line
}

\author{
Sami Dogan, Fuat Cetin, Emin Gurleyik \\ Department of Surgery, Duzce University Medical Faculty, Duzce, Turkey
}

\begin{abstract}
Purpose: Surgical excision is the preferred treatment modality for sacrococcygeal pilonidal sinus (PS). Notably, the desirable features of an ideal surgical intervention are excision with minimal tissue loss, closure without tension, and a lateral suture line. The present study aimed to investigate early outcomes of surgical excision through the inverse $D(0)$ incision based on tissue loss, wound tension, and suture line location.

Methods: This prospective study was comprised of 80 patients with PS in whom excision of PS was performed through the ' $O$ ' incision to minimize tissue loss with a tensionless primary surgical wound closure. The suture line was located laterally in all patients. Early and late postoperative complications, duration of hospital stay, return to work, and recurrence rates were investigated. The mean duration of the follow-up period was 36 months.

Results: Sixty-three patients $(78.8 \%)$ were male. PS in all patients was surgically removed by subcutaneous excision through a ' $O$ ' incision. Laterally placed surgical wounds were closed primarily with interrupted vertical mattress sutures. No general complications were encountered. Five patients $(6.3 \%)$ experienced early postoperative surgical site complications. On average, the duration of hospital stay and return to work were 2.4 days and 3.8 days, respectively. Recurrence was seen in 1 case (1.3\%) during the follow-up period. Satisfaction score was high in $83.8 \%$ of patients.

Conclusion: The method of sinus excision using the ' $O$ ' incision with a primary suture facilitates excision with minimal tissue loss and closure without tension with an off-midline suture. It is both a simple and effective surgical technique for the treatment of sacrococcygeal PS.
\end{abstract}

[Ann Surg Treat Res 2019;97(5):261-265]

Key Words: Complication, Pilonidal sinus, Recurrence, Surgery

\section{INTRODUCTION}

Although sacrococcygeal pilonidal sinus (PS) is widespread, this condition and its optimal treatment have remained controversial since it was first described by Mayo in 1833 [1]. PS can occur in many parts of the body but is predominant in the natal cleft in the sacrococcygeal region.

Despite the availability of nonsurgical methods, surgery is the preferred treatment for PS [2]. Surgical treatment is divided into 2 groups: open and closed. In open surgical procedures, the excision is left open in anticipation of secondary healing. Closed methods involve excision with primary closure to the midline or lateral suture line. Several closed methods of excision and suturing techniques have been described for surgical treatment of PS [3-7]. In the last 5-10 years, minimallyinvasive procedures, such as endoscopic methods, laser therapy, microsinusectomy, and pit-picking, have been described for the treatment of PS, with evidence of short-term positive results
Received June 7, 2019, Revised August 21, 2019,

Accepted September 18, 2019

\section{Corresponding Author: Sami Dogan}

Department of Surgery, Duzce Universitesi, Arastırma Uygulama Hastanesi, Konuralp, 81650 Duzce, Turkey

Tel: +90-380-542-1390, Fax: +90-380-542-1387

E-mail: samidogan@hotmail.com

ORCID: https://orcid.org/0000-0003-2798-4049

\section{Copyright (c) 2019, the Korean Surgical Society}

(c) Annals of Surgical Treatment and Research is an Open Access Journal. All articles are distributed under the terms of the Creative Commons Attribution NonCommercial License (http://creativecommons.org/licenses/by-nc/4.0/) which permits unrestricted non-commercial use, distribution, and reproduction in any medium, provided the original work is properly cited. 
[5,8-13].

We hypothesized that sinus excision with minimal tissue loss leads to a tensionless closure of the surgical wound. Minimal tissue loss facilitates tensionless suturing, thereby promoting wound healing. Our method in the present study was planned as less invasive to excise minimal tissue with a tensionless closure of the surgical defect. Expectations from the treatment included lesser invasiveness, shorter hospital stay, faster recovery, better cosmetic appearance, and lower recurrence rate. In the present study, we aimed to perform excision of the sacrococcygeal PS through an inverse D "(O)" incision with minimal tissue removal followed by primary tensionless closure with a lateral suture line.

\section{METHODS}

The study was approved by the Institutional Review Board (IRB No. 2015-01-01). Our series was comprised of 80 adult patients with chronic sacrococcygeal PS who presented to our department. They were classified per the navicular area of PS classification as types 1-4 [14]. After determining the size, location, and extent of the sinus in the subcutaneous area through ultrasound imaging, a decision was made regarding the surgical technique to be used. The surgical method was explained to the patients in a way they could understand, using detailed pictures. Full informed consent was obtained from the patients. Age, sex, family history, duration of illness, preoperative interventions, complaint upon admission, number and site of sinus pits, early and late complications, and recurrence rates were recorded for all patients. Patients who had undergone surgery through the $D(0)$ incision with sinus excision and the primary suture between January 2015 and June 2017 were followed up on. A single surgeon performed the sinus excisions through the ' $O$ ' incision with primary sutures. The preference for ' $O$ ' incision technique for PS is based on the surgeon's position. A surgeon on the right side of the table and left side of the prone patient can easily dissect through the ' $O$ ' incision. The average duration of follow-up was 36 months (range, 20-48 months).

\section{Ultrasound imaging}

Before surgical planning, ultrasound imaging of the region was performed to determine the extent of the sinus in the subcutaneous area. The projection of the sinus was marked on the skin under ultrasound guidance on the same day of surgery.

\section{Surgical technique}

The surgery was performed with the patient in a prone position under spinal anesthesia. The intergluteal fold was separated using tape, and a probe was used to dilate the sinus opening followed by instillation of methylene blue through it.
Only the sinus opening(s) was incised using a No. 11 scalpel. The subcutaneous area was explored through the ' $O$ ' incision. The cyst was released from the posterior and right sides using electrocautery under the left lateral skin. The sinus was then excised through the left lateral opened area. After careful hemostasis, the subcutaneous tissue was approximated using 3-0 Vicryl sutures (Johnson \& Johnson, New Brunswick, NJ, USA). A negative pressure drain was placed in the subcutaneous space. The skin at the sinus excision site was closed using mattress sutures. The surgical site was packed with a pressure dressing. The drain was removed on postoperative day 2 , and the patient was discharged. Skin sutures were removed between the 10th and 15th postoperative days.

\section{Follow-up}

After discharge, patients were called for control and skin suture removal in the first and second weeks. Subsequently,

Table 1. Pilonidal sinus types according to navicular area concept, patients' features, and pilonidal sinus disease history

\begin{tabular}{|c|c|}
\hline Patients' features & Value \\
\hline Primary pilonidal sinus & 80 \\
\hline Type 1 & $18(22.5)$ \\
\hline Type 2 & $25(31.2)$ \\
\hline Type 3 & $22(27.5)$ \\
\hline Type 4 & $15(18.8)$ \\
\hline Male sex & $63(78.8)$ \\
\hline Type 1 & $14 / 18(77.8)$ \\
\hline Type 2 & $19 / 25(76.0)$ \\
\hline Type 3 & $17 / 22(77.3)$ \\
\hline Type 4 & $13 / 15(86.7)$ \\
\hline Patients with family history & $18(22.5)$ \\
\hline Type 1 & 2 \\
\hline Type 2 & 3 \\
\hline Type 3 & 5 \\
\hline Type 4 & 8 \\
\hline Patients with previous abscess drainage & $22(27.5)$ \\
\hline Type 1 & 0 \\
\hline Type 2 & 3 \\
\hline Type 3 & 9 \\
\hline Type 4 & 10 \\
\hline Mean duration of complaint (yr) & 2.1 \\
\hline Type 1 & 0.9 \\
\hline Type 2 & 2.0 \\
\hline Type 3 & 2.4 \\
\hline Type 4 & 3.5 \\
\hline Mean number of sinus pits & 2 \\
\hline Type 1 & 1.6 \\
\hline Type 2 & 1.8 \\
\hline Type 3 & 2.1 \\
\hline Type 4 & 2.7 \\
\hline
\end{tabular}

Values are presented as number (\%) unless otherwise indicated. 

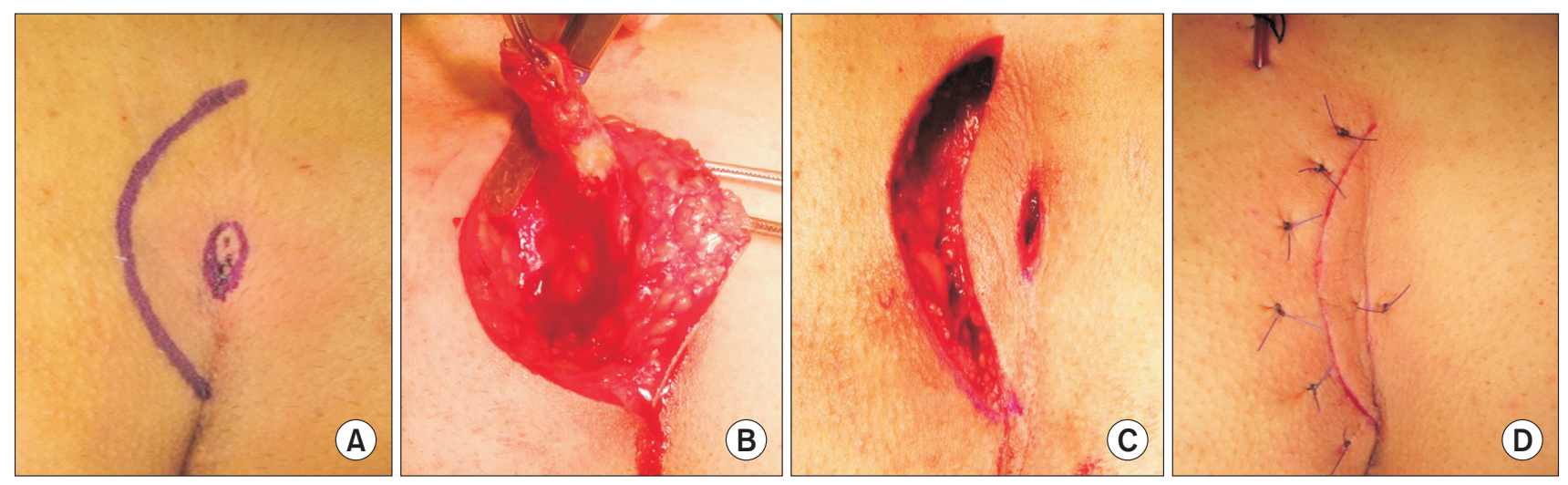

Fig. 1. Excision with minimal tissue loss, closure without tension, and off-midline suture. (A) Preoperative drawing of the inverse $\mathrm{D}(\mathrm{O})$ incision and sinus pits at the midline. (B) Subcutaneous excision of the sinus via inverse ' $\mathrm{O}$ ' incision. (C) Operative wound after excision with minimal tissue loss. (D) Primary, tensionless, and off-midline closure of surgical wound.

Table 2. Postoperative outcomes according to pilonidal sinus types

\begin{tabular}{cc}
\hline \multicolumn{1}{c}{ Variable } & Results \\
\hline General complication & None \\
Type 1 & None \\
Type 2 & None \\
Type 3 & None \\
Type 4 & None \\
Early local complications ${ }^{\text {a) }}$ & \\
Type 1 & None \\
Type 2 & None \\
Type 3 & 2 \\
Type 4 & 3 \\
Duration of hospital stay (day), mean (range) & $2.4(2-3)$ \\
Type 1 & 2.1 \\
Type 2 & 2.3 \\
Type 3 & 2.5 \\
Type 4 & 2.8 \\
Duration of return to work (day), mean (range) & $3.8(2-5)$ \\
Type 1 & 2.9 \\
Type 2 & 3.4 \\
Type 3 & 4.1 \\
Type 4 & 4.7 \\
Recurrence, $\mathrm{n}$ (\%) & $1(1.3)$ \\
Type 1 & None \\
Type 2 & None \\
Type 3 & None \\
Type 4 & 1 \\
\hline
\end{tabular}

${ }^{a}$ Early local complications -- 5 (6.3\%): wound infection 3, hematoma 2.

they were followed up by the authors at quarterly hospital visits in the first year and yearly thereafter.

Patient's satisfaction was evaluated during hospital visits with a numeric scale from 1 to 5 . Patients chose their satisfaction score between point 1 most satisfied and point 5 most dissatisfied.
Table 3. Patient satisfaction scores according to pilonidal sinus types

\begin{tabular}{lccccc}
\hline Score $^{\text {a) }}$ & Total & Type 1 & Type 2 & Type 3 & Type 4 \\
\hline 1 & $47(58.8)$ & $15(83.3)$ & $18(72)$ & $8(36.4)$ & $6(40)$ \\
2 & $20(25)$ & $3(16.7)$ & $7(28)$ & $8(36.4)$ & $2(13.3)$ \\
3 & $8(10)$ & - & - & $5(22.7)$ & $3(20)$ \\
4 & $4(5)$ & - & - & $1(4.5)$ & $3(20)$ \\
5 & $1(1.2)$ & - & - & - & $1(6.7)$ \\
Total & 80 & 18 & 25 & 22 & 15 \\
\hline
\end{tabular}

Values are presented as number (\%).

a) 1 , most satisfied; 5, most dissatisfied.

\section{RESULTS}

The study was comprised of 80 patients with a mean age of 27 years, of which 63 (78.8\%) were male. Upon disease historytaking, 22 cases were noted to have had previous intervention (abscess drainage). All 4 types of classifications, based on the navicular area concept, were observed among the patients (Table 1) [14]. All patients had elective admission. The primary symptoms were continuous discharge in 8 patients, intermittent discharge in 52, and swelling in 20. The PS excisions were performed through the ' $O$ ' incision. The wound was primarily closed with a suture line away from the midline (Fig. 1). The sinus cavity was incidentally entered during dissection in 2 and 4 patients with type 3 and type 4 PS, respectively.

Five patients (6.3\%) had early postoperative surgical site complications. Only 2 patients required postoperative analgesia. On average, the duration of hospital stay was 2.4 days, and return to regular activity was 3.8 days. One patient $(1.3 \%)$ had 
a recurrence during the follow-up period (Table 2). Significant deformity was not noted in this series. Patient satisfaction score was point 1 and 2 in 67 patients (83.8\%) (Table 3).

\section{DISCUSSION}

The primary aim of the present technique was excision of the sinus with minimal tissue loss to facilitate primary closure of surgical wound without suture line tension. The second aim was the lateral placement of the suture line, away from the midline. Minimal surgical defect after excision that can be sutured without tension facilitates better wound healing. Therefore, a laterally placed suture line is advisable to promote a better healing process. Moreover, the surgeon's position on the right side of the table and left side of the patient facilitates easy subcutaneous tissue dissection through ' $O$ ' incision.

In our study, only the cyst and sinus orifices were removed with minimal tissue loss, thereby allowing primary closure of the surgical wound with minimum tension. In a similar study, extensive resection was performed through minimallyinvasive surgery in pediatric patients, wherein the excision was performed using a tool (trephine) and left open without sutures. However, the cases of this minimally-invasive surgery had high (28\%) reoperation rates, with the most frequent local complications of bleeding (11\%), pain (36\%), and abscess (33\%) [15]. Nonetheless, we believe that we achieved good results with minimal tissue loss and primary closure. In our series, the duration of healing was shorter with significantly lower bleeding and infection rates. Soll et al. [16] reported a recurrence rate of $7 \%$ after a four-year follow-up in patients who had undergone sinusectomy. Full activity was resumed after one day, showing good results. Notably, however, disadvantages associated with sinusectomy are apparent if the sinusectomy site is left open when the sinus is large. On the other hand, resection is difficult with a smaller sinus incision, and there is a risk of remnant sinus tissue after surgery [16]. Brusciano et al. [17] reported the results of a D-shaped asymmetric excision of PS and primary closure. Despite primary closure, this technique encountered more skin and tissue loss and had one- and fiveyear recurrence rates of $2 \%$ and $6 \%$, respectively, which could be attributed to tension in the suture line. Our study evidenced a favorable result in that the middle-term recurrence rate was low during the follow-up period of 36 months. The positive findings of short hospital stay, a quick return to work, and low recurrence rate observed in our study are primarily because of our excision and closure technique with less tissue loss and reduced suture line tension. Several studies have demonstrated that operations performed using the conventional method reported recurrence rates ranging from $0 \%$ to $41 \%$, whereas recurrence rates ranged from $6 \%$ to $16 \%$ in cases termed minimally invasive [10].
In surgical treatments using closure techniques, the offmidline methods are preferred by many authors, and these do not have the disadvantages of techniques that use midline sutures. Our minimal PS excision via the ' $O$ ' incision provides almost tensionless wound closure away from the midline. We firmly believe that the lateral suture line promotes better wound healing. Contrarily, excision with primary closure, as proposed by some authors, observed an increased recurrence rate because of midline scar owing to a shorter healing time. Additionally, an investigation on the practice parameters of PS management reported 9 individual studies that showed the recurrence rates were reduced by $60 \%$ in those treated with midline and off-midline closure methods after excision $[1,2,17,18]$. Kose et al. [19] reported that off-midline closure techniques are superior to primary midline closure technique regarding general complication, wound dehiscence, and recurrence rates. Based on our favorable results, we firmly believe that excision of PS with minimal tissue loss through an incision away from the midline is justified. Our surgical technique is highly recommended because both the ' $O$ ' incision and tensionless closure are off-midline. Our patients' high satisfaction score supports our results of excision with minimal tissue loss and tensionless closure. There has been a consensus that operations with a lateral incision and closure are more effective than those using midline excision and closure as evidenced by several randomized controlled studies and subsequent metaanalysis [3,20]. Zorlu et al. [18] reported that techniques with primary lateral suture line might be offered as a viable surgical therapeutic option among off-midline closure approaches. Similarly, in our off-midline closure method, excision of the PS through the ' $O$ ' incision was performed with minimal tissue loss and tensionless closure of wound edges in a lateral position.

In conclusion, our present technique aims to excise the sacrococcygeal PS subcutaneously with minimal tissue loss through a ' $O$ ' incision that facilitates smooth approximation of wound edges after primary closure. An off-midline and tensionless primary wound closure offers better cosmetic healing, reduced pain, and an earlier return to daily activities. With proper evaluation and sound indications in selected cases, the recurrence rate will be reduced after subcutaneous sinus excision. An operation involving the ' $O$ ' incision and primary suture method is both a simple and effective surgical technique for the treatment of PS.

\section{CONFLICTS OF INTEREST}

No potential conflict of interest relevant to this article was reported. 


\section{REFERENCES}

1. Steele SR, Perry WB, Mills S, Buie WD; Standards Practice Task Force of the American Society of Colon and Rectal Surgeons. Practice parameters for the management of pilonidal disease. Dis Colon Rectum 2013;56:1021-7.

2. de Parades V, Bouchard D, Janier M, Berger A. Pilonidal sinus disease. J Visc Surg 2013;150:237-47.

3. Cheetham M. Lateral incision surgery for pilonidal sinus: death of a dogma. World J Surg 2012;36:436.

4. Sewefy AM, Hassanen A, Atyia AM, Saleh SK. Karydakis flap with compressing tieover interrupted sutures without drain versus standard karydakis for treatment of sacrococcygeal pilonidal sinus disease. Dis Colon Rectum 2017;60:514-20.

5. Iesalnieks I, Deimel S, Schlitt HJ. "Pit picking" surgery for patients with pilonidal disease: mid-term results and risk factors. Chirurg 2015;86:482-5.

6. Iesalnieks I, Ommer A, Petersen S, Doll D, Herold A. German national guideline on the management of pilonidal disease. Langenbecks Arch Surg 2016;401:599-609.

7. Cetin K, Sikar HE, Kocaoglu AE, Kundes MF, Karahan M, Kaptanoglu L. Evaluation of intradermal absorbable and mattress sutures to close pilonidal sinus wounds with Limberg flap: a prospective randomized comparative study. Ann Surg Treat Res 2018;94:88-93.
8. Giarratano G, Toscana C, Shalaby M, Buonomo O, Petrella G, Sileri P. Endoscopic pilonidal sinus treatment: longterm results of a prospective series. JSLS 2017;21(3). pii: e2017.00043. https://doi. org/10.4293/JSLS.2017.00043.

9. Suarez Valladares MJ, Rodriguez Prieto MA. Neodymium-doped yttrium aluminium garnet laser to treat primary pilonidal cysts: an alternative treatment. $\mathrm{Br} \mathrm{J}$ Dermatol 2018;178:e127-8.

10. Di Castro A, Guerra F, Levi Sandri GB, Ettorre GM. Minimally invasive surgery for the treatment of pilonidal disease. The Gips procedure on 2347 patients. Int J Surg 2016:36(Pt A):201-5.

11. Milone M, Fernandez LM, Musella M, Milone F. Safety and efficacy of minimally invasive video-assisted ablation of pilonidal sinus: a randomized clinical trial. JAMA Surg 2016;151:547-53.

12. Hap W, Frejlich E, Rudno-Rudzinska J, Kotulski K, Kurnol K, Hap K, et al. Pilonidal sinus: finding the righttrack for treatment. Pol Przegl Chir 2017;89:68-75.

13. Dessily M, Charara F, Ralea S, Alle JL. Pilonidal sinus destruction with a radial laser probe: technique and first Belgian experience. Acta Chir Belg 2017;117:164-8.

14. Tezel E. A new classification according to navicular area concept for sacrococcygeal pilonidal disease. Colorectal Dis 2007:9: 575-6.
15. Speter C, Zmora O, Nadler R, Shinhar D, Bilik R. Minimal incision as a promising technique for resection of pilonidal sinus in children. J Pediatr Surg 2017;52:1484-7.

16. Soll C, Dindo D, Steinemann D, Hauffe T, Clavien PA, Hahnloser D. Sinusectomy for primary pilonidal sinus: less is more. Surgery 2011;150:996-1001.

17. Brusciano L, Limongelli P, Del Genio G, Tolone S, Amoroso V, Docimo G, et al. D-shape asymmetric excision of sacrococcygeal pilonidal sinus with primary closure, suction drain, and subcuticular skin closure: an analysis of risks factors for long-term recurrence. Surg Innov 2015; 22:143-8.

18. Zorlu M, Sahiner IT, Zobac1 E, Kocak C, Yastı AC, Dolapc1 M. Early results with the Mutaf technique: a novel off-midline approach in pilonidal sinus surgery. Ann Surg Treat Res 2016;90:265-71.

19. Kose E, Hasbahceci M, Tonyali H, Karagulle M. Comparative analysis of the same technique-the same surgeon approach in the surgical treatment of pilonidal sinus disease: a retrospective cohort study. Ann Surg Treat Res 2017:93:82-7.

20. McCallum I, King PM, Bruce J. Healing by primary versus secondary intention after surgical treatment for pilonidal sinus. Cochrane Database Syst Rev 2007;(4): CD006213. 